\title{
Seismicity near the hypocenter of the 2011 off the Pacific coast of Tohoku earthquake deduced by using ocean bottom seismographic data
}

\author{
Kensuke Suzuki ${ }^{1}$, Ryota Hino ${ }^{1}$, Yoshihiro Ito ${ }^{1}$, Yojiro Yamamoto $^{2}$, Syuichi Suzuki ${ }^{1}$, Hiromi Fujimoto ${ }^{1}$, Masanao Shinohara ${ }^{3}$, \\ Masao $\mathrm{Abe}^{4}$, Yoshiharu Kawaharada ${ }^{4}$, Yohei Hasegawa ${ }^{4}$, and Yoshiyuki Kaneda ${ }^{2}$ \\ ${ }^{1}$ Research Center for Prediction of Earthquakes and Volcanic Eruptions, Graduate School of Science, Tohoku University, \\ 6-6 Aza-Aoba, Aramaki, Aoba-ku, Sendai 980-8578, Japan \\ ${ }^{2}$ Japan Agency for Marine-Earth Science and Technology, 3175-25 Showa-machi, \\ Kanazawa-ku, Yokohama, Kanagawa 236-0001, Japan \\ ${ }^{3}$ Earthquake Research Institute, University of Tokyo, Yayoi 1-1-1, Bunkyo-ku, Tokyo 113-0032, Japan \\ ${ }_{4}^{4}$ Japan Meteorological Agency, 1-3-4, Otemachi, Chiyoda-ku, Tokyo 100-8122, Japan
}

(Received December 27, 2011; Revised April 26, 2012; Accepted April 27, 2012; Online published January 28, 2013)

\begin{abstract}
We relocated hypocenters of the foreshock, mainshock, and aftershocks of the 2011 off the Pacific coast of Tohoku earthquake ( $M 9.0)$ in the middle part of the Japan Trench where the earthquake rupture initiated. Ocean Bottom Seismographs (OBSs), deployed in the area, recorded the earthquakes and these data provide improved images of the hypocenter distribution. The mainshock hypocenter was relocated slightly westward from that reported by Japan Meteorological Agency (JMA), placing it near the intersection between the plate boundary and the Moho of the overriding plate. The foreshock seismicity mainly occurred on the trenchward side of the mainshock hypocenter, where the Pacific slab contacts the island arc crust. The foreshocks were initially activated at the up-dip limit of the seismogenic zone $\sim 30 \mathrm{~km}$ trenchward of the largest foreshock $(M 7.3$, two days before the mainshock). After the $M-7.3$ earthquake, intense interplate seismicity, accompanied by epicenters migrating toward the mainshock hypocenter, was observed. The focal depth distribution changed significantly in response to the $M-9$ mainshock. Earthquakes along the plate boundary were almost non-existent in the area of huge coseismic slip, whereas earthquakes off the boundary increased in numbers in both the upper and the lower plates.
\end{abstract}

Key words: Tohoku-oki earthquake, Ocean Bottom Seismograph, seismicity, Miyagi-oki.

\section{Introduction}

On March 11, 2011, a massive interplate earthquake ( $M$ 9.0), the 2011 off the Pacific coast of Tohoku earthquake (hereafter, the Tohoku-oki earthquake), occurred along the Japan Trench subduction zone (Fig. 1), producing strong ground shaking and high tsunamis that devastated the Pacific coast of northeastern Japan. In this region, interplate thrust faulting earthquakes along the subduction interface have occurred frequently, accommodating the relative motion between the subducting Pacific plate and the overriding North American plate. Among them, large earthquakes with $M 7-8$ have repeatedly occurred at approximately fifty-year intervals. Some studies have demonstrated that these large interplate earthquakes can be interpreted as recurrent ruptures of persistent asperities whose locations and sizes are time invariant (e.g., Nagai et al., 2001; Yamanaka and Kikuchi, 2004). In the middle part of the subduction zone, where the hypocenter of the Tohoku-oki earthquake is located, the recurrence of interplate earthquakes of $M \sim 7.5$ (Miyagi-oki earthquakes) has been established on the basis of investigations into the past seismicity (http://www.jisin.go.jp/main/choukihyoka/kaikou.htm).

Copyright (C) The Society of Geomagnetism and Earth, Planetary and Space Sciences (SGEPSS); The Seismological Society of Japan; The Volcanological Society of Japan; The Geodetic Society of Japan; The Japanese Society for Planetary Sciences; TERRAPUB.

doi:10.5047/eps.2012.04.010
The most recent such earthquake (M 7.2) occurred on August 16,2005 . This earthquake was considered to be a partial re-rupturing of the asperities responsible for the recurrent Miyagi-oki earthquakes, because the size of the rupture area was smaller than that of the previous 1978 Miyagi-oki earthquake (Okada et al., 2005; Wu et al., 2008).

The seismicity near the Miyagi-oki region became more active than usual in the beginning of February 2011, almost one month before the Tohoku-oki earthquake occurred. Before the Tohoku-oki earthquake, the largest earthquake was an interplate earthquake with $M 7.3$, which occurred on March 9, 2011 (Fig. 1). Intensive aftershock seismicity, including moderate-sized ( $M$ 5-6) earthquakes, followed that event. In this paper, we refer to the earthquakes that preceded the $M-9$ earthquake as foreshocks of the Tohokuoki earthquake because of their proximity to the Tohokuoki earthquake in terms of time and space. Further, from the hypocenter catalogue published by JMA, it has been pointed out that the epicenters of the foreshocks migrated toward the hypocenter of the mainshock of the Tohoku-oki earthquake (Ando and Imanishi, 2011; Kato et al., 2012).

The determination of precise hypocenter locations is important for understanding the mechanisms of earthquake generation, because they can be used as the basis to compare fault rupture models and underground structure variations. Interplate earthquakes typically occur in offshore areas, far away from onshore seismic stations, and, hence, it 


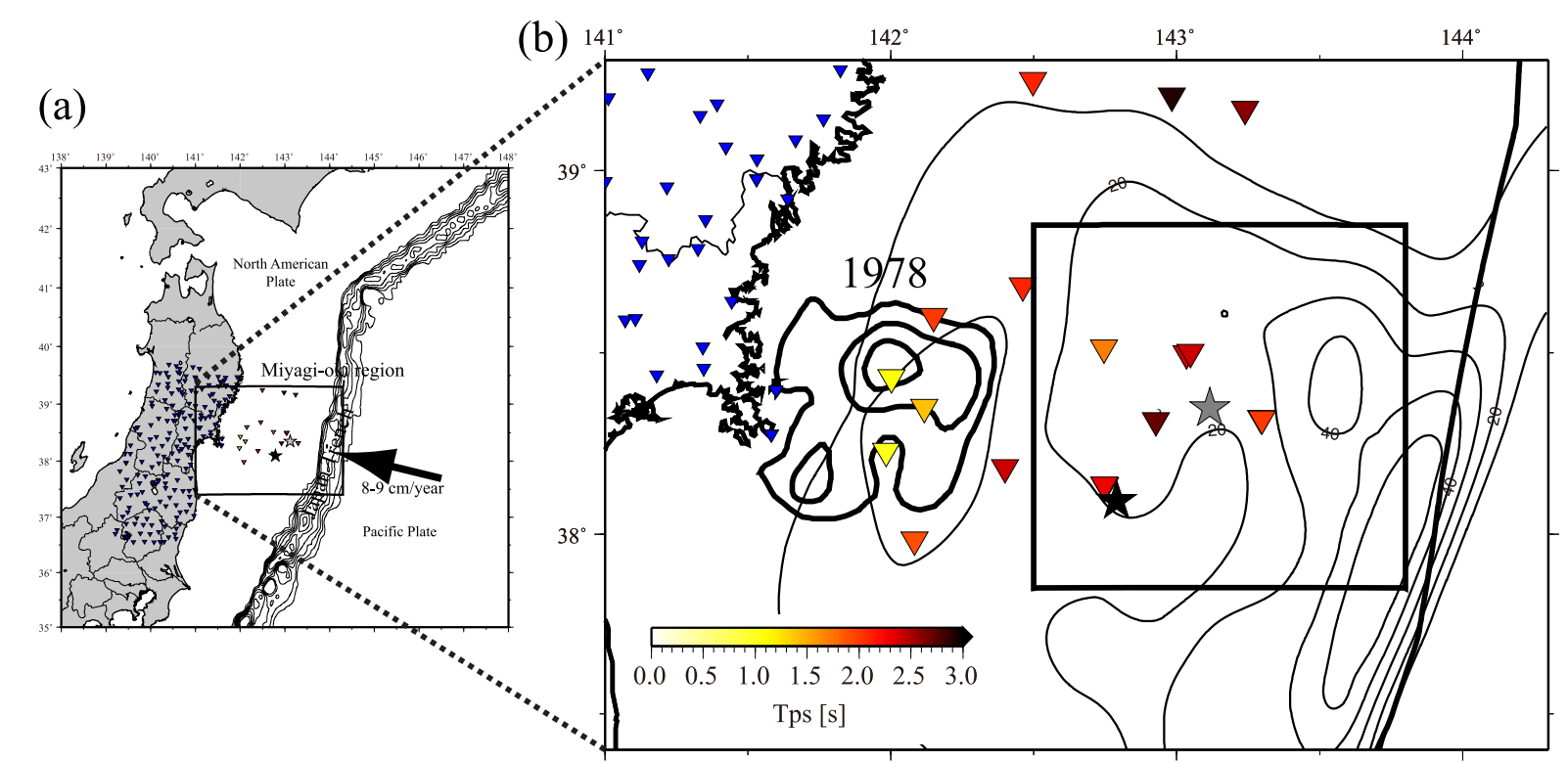

Fig. 1. Tectonic setting. The black and gray stars indicate the 2011 mainshock (March 11, 2011) and the largest foreshock (March 9, 2011) epicenters, respectively. Stations are shown by colored (OBSs) and blue (onshore stations) inverted triangles. (a) Map of the study area. The rectangle represents the Miyagi-oki region. The black arrow shows the direction of the Pacific and North American plate convergence (DeMets et al., 1994). (b) Map view of station distribution in the Miyagi-oki region shown in Fig. 1(a). The rectangle shows the foreshock area discussed in this study. Rupture areas of the mainshock (Lay et al., 2011) and the 1978 earthquake (Yamanaka and Kikuchi, 2004) are shown by the black contour. The black line is the Japan Trench.

tends to be difficult to determine their hypocenter locations, especially focal depths, with adequate precision. Therefore, one of the reasonable methods to improve hypocenter locations is the use of OBSs for providing observations close to the hypocenters (e.g., Sakai et al., 2005; Hino et al., 2006).

Since 2002, we have repeatedly deployed and retrieved OBSs to monitor seismicity in the Miyagi-oki region. In the course of this repeated deployment, we observed a sequence of foreshocks, the mainshock, and aftershocks of the 2011 Tohoku-oki earthquake from a close vicinity by using OBSs deployed in 2010 (Fig. 1(b)). In this study, we have relocated the hypocenter distribution in the Miyagi-Oki region by integrating offshore OBS data with onshore station observations. Based on the relocated hypocenter distribution, we discuss the spatio-temporal variations in seismicity and also how structural variations control the faulting process along the plate boundary.

\section{Data and Method}

\subsection{Seismic observations}

In northeastern Japan, dense seismic networks are operated by the National Research Institute for Earthquake Science and Disaster Prevention (NIED), Tohoku University and JMA. We used offshore data obtained by OBSs, in addition to these onshore data, to relocate the hypocenters. Figure 1 shows the distribution of the OBSs and the onshore stations used in this study (also see Table 1). The OBS network covered the area around the hypocenter of the $M$ 9 mainshock that had large coseismic displacement (e.g., Lay et al., 2011). Although the area covered by the OBS network is considerably smaller than the entire mainshock rupture region, our OBS observation close to the mainshock hypocenter provided us with improved hypocenter locations, thereby enabling a detailed discussion of spatio- temporal variations in the region as well as relationships with the crustal structure in the area having the largest coseismic deformation.

Our OBSs were of the free-fall/pop-up type and equipped with short-period (1 or $4.5 \mathrm{~Hz})$ three-component geophones. We have assumed that the timing error of the OBS clock can be expressed as a linear function of time, and we corrected for the error by measuring the time difference between the OBS clock and a time standard synchronized to the GPS timing, before deployment and after retrieval. The correction resulted in a timing accuracy of approximately $\pm 0.05 \mathrm{~s}$. The horizontal position of the OBS was estimated by an acoustic ranging triangulation method applied at the deployment or retrieval of the instruments. The location errors were approximately $\pm 100 \mathrm{~m}$ at most. The water depths of the OBS sites were measured by echo sounders (or multibeam sonars) aboard research vessels at the time of the deployment.

On March 11, when the Tohoku-oki earthquake occurred, 23 OBSs were in operation. For this study, we processed the continuous seismic waveform data obtained by 15 OBSs that were successfully recovered until June 2011. We picked the arrival times of $P$ - and $S$-waves from the timecorrected waveform records, in addition to those of onshore stations. We limited our study to earthquakes occurring from January 1 to May 24, 2011, in our hypocenter relocation. Furthermore, we selected the earthquakes located within the range $37.8-39.0^{\circ} \mathrm{N}$ and $141.5-145^{\circ} \mathrm{E}$, in accordance with the JMA catalogue. We did not make additional event detection by using the OBS waveform records in this study. We processed all the earthquakes with a magnitude 2.0, or larger, before the occurrence of the mainshock. However, only aftershocks with $M \geq 3.5$ were included in our hypocenter relocation, because the vast number of 
Table 1. Free-fall/pop-up and cabled OBSs used in this study.

\begin{tabular}{cccccc}
\hline Station & $\begin{array}{c}\text { Observation } \\
\text { period }\end{array}$ & $\begin{array}{c}\text { Lat. } \\
\left({ }^{\circ} \mathrm{N}\right)\end{array}$ & $\begin{array}{c}\text { Lon. } \\
\left({ }^{\circ} \mathrm{E}\right)\end{array}$ & $\begin{array}{c}\text { Dep. } \\
(\mathrm{km})\end{array}$ & $\begin{array}{c}T_{p s} \\
(\mathrm{~s})\end{array}$ \\
\hline S01 & $2010 / 11 / 05 \sim 2011 / 05 / 22$ & 38.3502 & 142.1169 & 0.524 & 1.4 \\
S02 & $2010 / 11 / 05 \sim 2011 / 05 / 22$ & 37.9836 & 142.0827 & 0.538 & 1.9 \\
S03 & $2010 / 11 / 05 \sim 2011 / 04 / 14$ & 38.1834 & 142.3997 & 1.052 & 2.4 \\
S08 & $2010 / 05 / 15 \sim 2011 / 02 / 01$ & 38.1336 & 142.7485 & 1.532 & 2.3 \\
S10 & $2010 / 10 / 01 \sim 2011 / 03 / 19$ & 38.4984 & 143.0341 & 1.981 & 2.4 \\
S14 & $2010 / 07 / 01 \sim 2011 / 05 / 23$ & 38.5138 & 142.7457 & 1.459 & 1.7 \\
S15 & $2010 / 07 / 01 \sim 2011 / 05 / 23$ & 38.3138 & 142.9276 & 1.454 & 2.7 \\
S18 & $2010 / 07 / 01 \sim 2011 / 03 / 19$ & 38.3191 & 143.2960 & 2.770 & 2.0 \\
S21 & $2010 / 11 / 05 \sim 2011 / 05 / 22$ & 38.4319 & 142.0019 & 0.358 & 1.1 \\
S22 & $2010 / 11 / 05 \sim 2011 / 05 / 22$ & 38.2292 & 141.9838 & 0.299 & 1.0 \\
S27 & $2010 / 11 / 05 \sim 2011 / 05 / 22$ & 38.6003 & 142.1501 & 0.545 & 2.0 \\
LS1 & $2010 / 11 / 05 \sim 2011 / 04 / 14$ & 38.6840 & 142.4606 & 1.112 & 2.1 \\
NS08a & $2011 / 03 / 15 \sim 2011 / 04 / 19$ & 38.1354 & 142.7482 & 1.498 & 2.3 \\
NS10a & $2011 / 03 / 15 \sim 2011 / 04 / 19$ & 38.5016 & 143.0495 & 2.017 & 2.4 \\
NS18a & $2011 / 03 / 15 \sim 2011 / 04 / 19$ & 38.3181 & 143.2984 & 2.746 & 2.0 \\
OB1 & & 39.1667 & 143.239 & 2.480 & 2.6 \\
OB2 & & 39.2029 & 142.984 & 1.840 & 2.9 \\
OB3 & & 39.2451 & 142.498 & 1.057 & 2.1 \\
\hline
\end{tabular}

earthquakes after the mainshock made it difficult to process events with $M<3.5$. We selected 970 local earthquakes that occurred in the Miyagi-oki region. As a result, 43,464 and 29,523 picked arrival times of $P$ - and $S$-waves, respectively, were used.

\subsection{Initial hypocenters}

In this paper, we have used two stages for the hypocenter location process: (1) rough relocation of the JMA hypocenters by using a 1-D velocity model, and (2) hypocenter determination by using a 3-D structure model. Since the hypocenter locations reported in the JMA catalogue may be ill-constrained owing to the lack of close-in observations, we preferred to use those hypocenters determined by the first step as the initial hypocenters in stage (2).

In the first step of hypocenter determination, we applied station corrections for the OBS arrival time data. The observed arrival time data at the OBS stations were significantly delayed owing to low $P$ - and $S$-wave velocities in the sedimentary layer just beneath the seafloor. In the same way as described by Hino et al. (2000), we estimated the time delays due to the sedimentary layer from the arrivaltime differences $\left(T_{p s}\right)$ between the direct $P$ - and $S$-waves converted from the direct $P$-wave at the base of the sedimentary layer. Assuming constant $P$ - and $S$-wave velocities in the sediment and basement, the delay times $\left(\Delta T_{i}\right.$, $i=P, S)$ can be estimated as:

$$
\Delta T_{i}=T_{p s}\left(\frac{V_{p}^{\mathrm{s}} V_{s}^{\mathrm{s}}}{V_{p}^{\mathrm{s}}-V_{s}^{\mathrm{s}}}\right)\left(\frac{1}{V_{i}^{\mathrm{s}}}-\frac{1}{V_{i}}\right) .
$$

Here, $V_{p}^{\mathrm{s}}$ and $V_{p}$ are the $P$-wave velocities in the sediment and basement, respectively, and $V_{s}^{\mathrm{s}}$ and $V_{s}$ are the $S$-wave velocities in the sediment and basement, respectively. In this study, we assumed $V_{p}^{\mathrm{s}}$ and $V_{s}^{\mathrm{s}}$ to have constant values of $1.80 \mathrm{~km} / \mathrm{s}$ and $0.60 \mathrm{~km} / \mathrm{s}$, respectively. In the case of $V_{p}$ and $V_{s}$, we used the values at zero depth in the 1-D velocity model used for the hypocenter calculation.

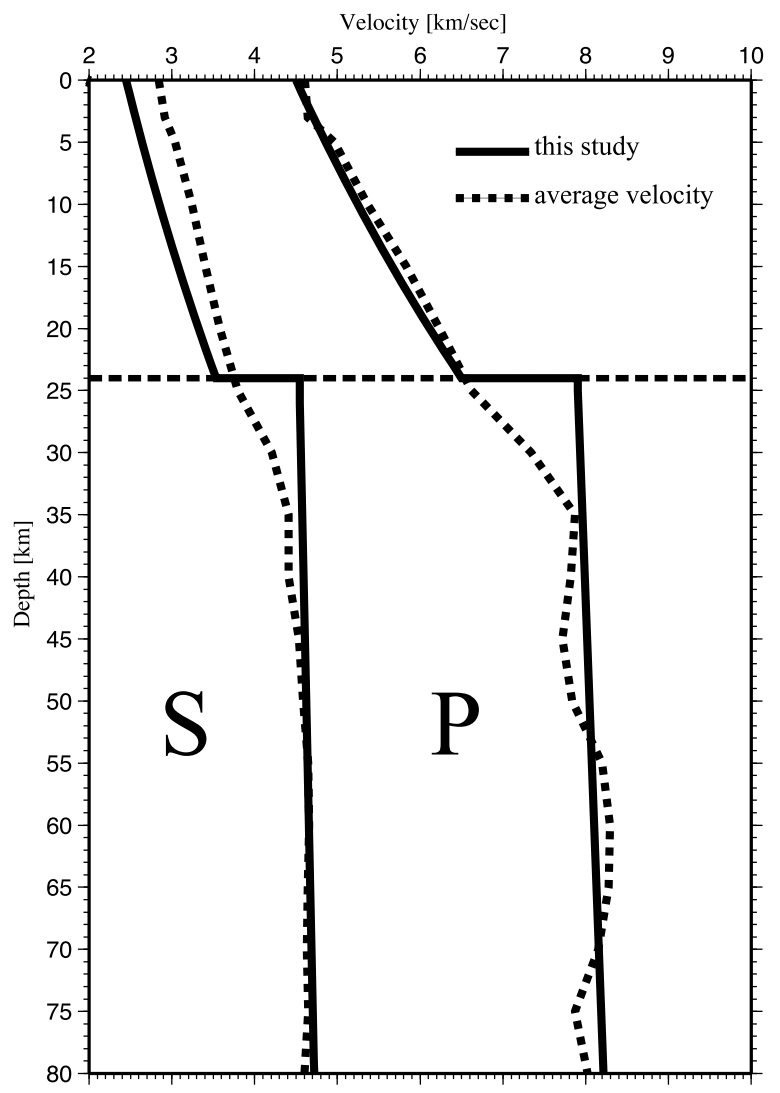

Fig. 2. The 1-D velocity structure model used to estimate the initial hypocenter locations. The solid and dashed lines are for the models used in this study and the average velocity of the 3-D model estimated by Yamamoto et al. (2008), respectively.

Our 1-D velocity model comprised two spherical shells corresponding to the crust and mantle layers (Fig. 2). We referred to the 3-D structure model estimated in the Miyagioki region by Yamamoto et al. (2008) to obtain appropriate values of $P$ - and $S$-wave velocities in the two layers, as well 


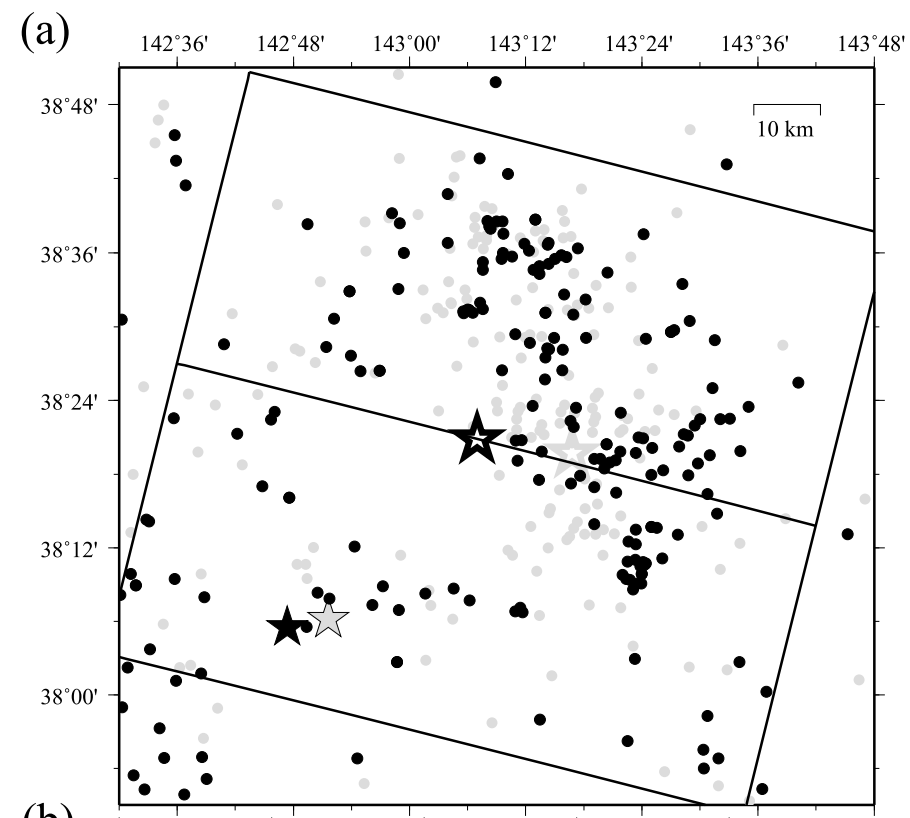

(b)
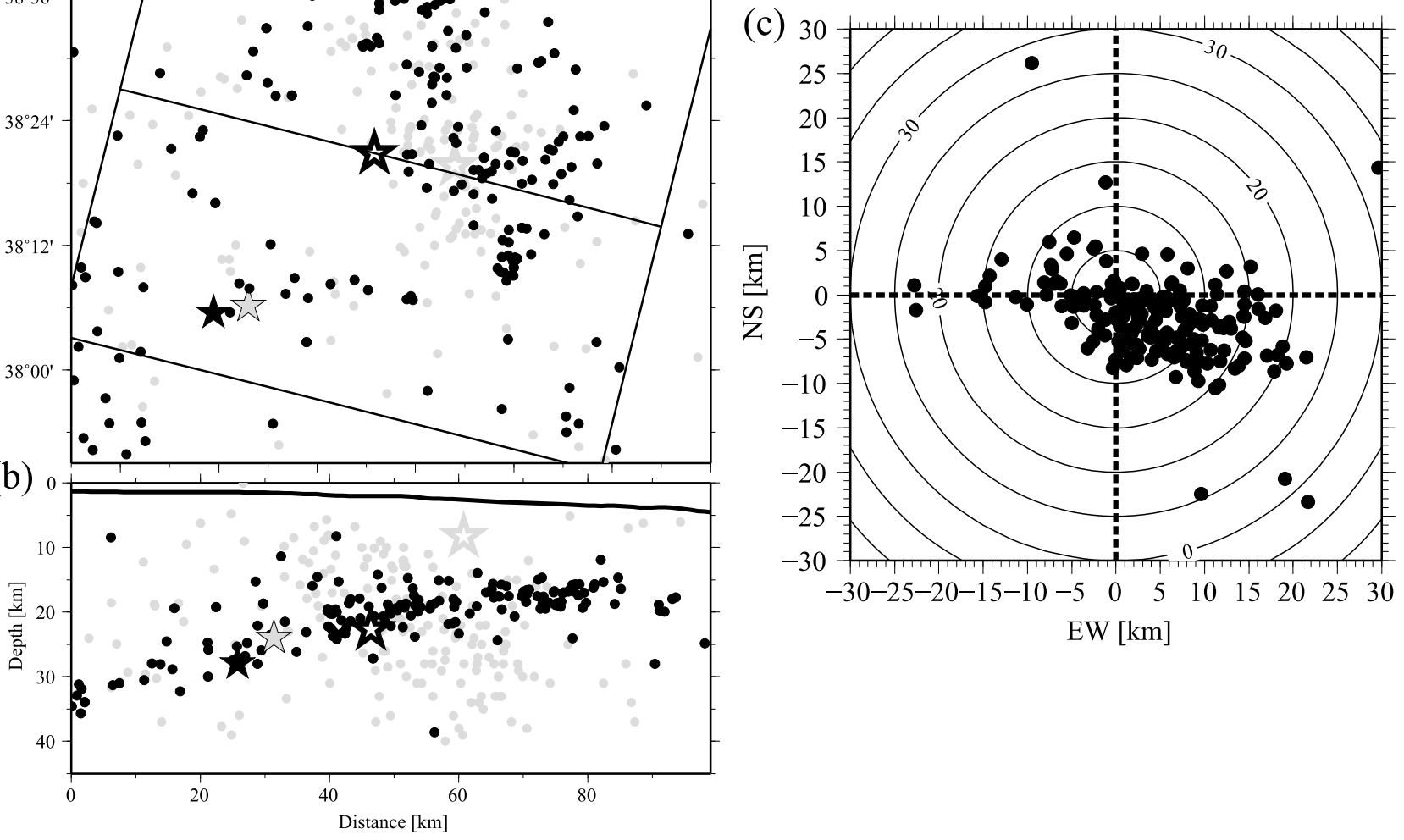

Fig. 3. Comparison of the hypocenter distribution between those relocated (black), and those from the JMA catalogue (gray), in the vicinity of the mainshock hypocenter shown in Fig. 1(b). The stars and open stars denote the mainshock and the largest foreshock, respectively. (a) Map view. (b) Cross-section of rectangle shown in the map view. (c) Epicenter distance from the JMA catalogue of the relocated earthquakes.

as the crustal thickness. In the model, the crustal thickness was $24 \mathrm{~km}$. The $V_{p} / V_{s}$ values were 1.84 and 1.74 for the crust and mantle, respectively.

\subsection{Relocation using a 3-D model}

The hypocenters estimated by the first step assuming the 1-D model were used as the initial hypocenters for a more detailed hypocenter determination using a 3-D structure model. We applied a code developed for DoubleDifference (DD) tomography method (Zhang and Thurber, 2003, 2006). We used a known 3-D model for travel time calculations, and travel time residuals were solved only for hypocenter coordinates and origin times, but not for velocity perturbations. The velocity model was kept unchanged in the process. For the 3-D velocity model, we used a model derived by Yamamoto et al. (2008) who investigated 3 -D $P$ - and $S$-wave structures using on- and off-shore passive seismic observation data. In our hypocenter relocation, travel time differences between event pairs, i.e., DD travel times, were used as well as absolute times. In this calculation, we selected stations and earthquakes from the relocated ones in the first step according to the following criteria: (1) stations whose distance to the earthquake epicenter was smaller than $200 \mathrm{~km}$; (2) earthquakes whose epicentral distance to the nearest station was smaller than 40 $\mathrm{km}$; and (3) earthquakes observed by stations with an az- imuth coverage larger than $90^{\circ}$. We obtained the DD data for event pairs with separations less than $15 \mathrm{~km}$. The DDs were calculated from arrival time data picked manually, after corrections for the travel time delays due to the surface sediments. Both the $P$ - and $S$-wave data were used in the relocation, but the weights of the $S$-wave data in the inversion were taken as $1 / 3$ of those of the $P$-wave data in order to account for the smaller picking accuracies of the $S$-wave readings. Our criteria were satisfied by 824 earthquakes, and we inverted the absolute $25,276(P) / 19,421(S)$ and relative $53,882(P) / 41,449(S)$ travel time data for hypocenter locations. The root mean square of the travel time residuals reduced from $1.10(P) / 1.23(S) \mathrm{s}$ for the initial hypocenters to $0.23(P) / 0.69(S)$ s after 30 iterations.

\section{Result}

Before discussing the relocated hypocenter distributions in detail, we present comparisons of our hypocenter locations with those in the JMA catalogue to demonstrate how the hypocenter distribution has been improved by adding the OBS data. Figures 3(a) and (b) show the epicenter distribution and focal depth distribution, respectively, around the hypocenter of the Tohoku-oki earthquake. The relocated hypocenters clearly show more concentrated patterns than the JMA hypocenters, especially in the focal depth distri- 
Table 2. Relocated hypocenters of the mainshock and largest foreshock.

\begin{tabular}{lccccc}
\hline & $\begin{array}{c}\text { Lat. } \\
\left({ }^{\circ}\right)\end{array}$ & $\begin{array}{c}\text { Lon. } \\
\left({ }^{\circ} \mathrm{E}\right)\end{array}$ & $\begin{array}{c}\text { Dep. } \\
(\mathrm{km})\end{array}$ & $\begin{array}{c}\text { Del. from JMA } \\
(\mathrm{km})\end{array}$ & $\begin{array}{c}\text { Az. to JMA } \\
\left({ }^{\circ}\right)\end{array}$ \\
\hline Mainshock & 38.0919 & 142.7897 & 28 & 6 & 258 \\
Largest foreshock & 38.2477 & 143.1164 & 23 & 14 & 279 \\
\hline
\end{tabular}
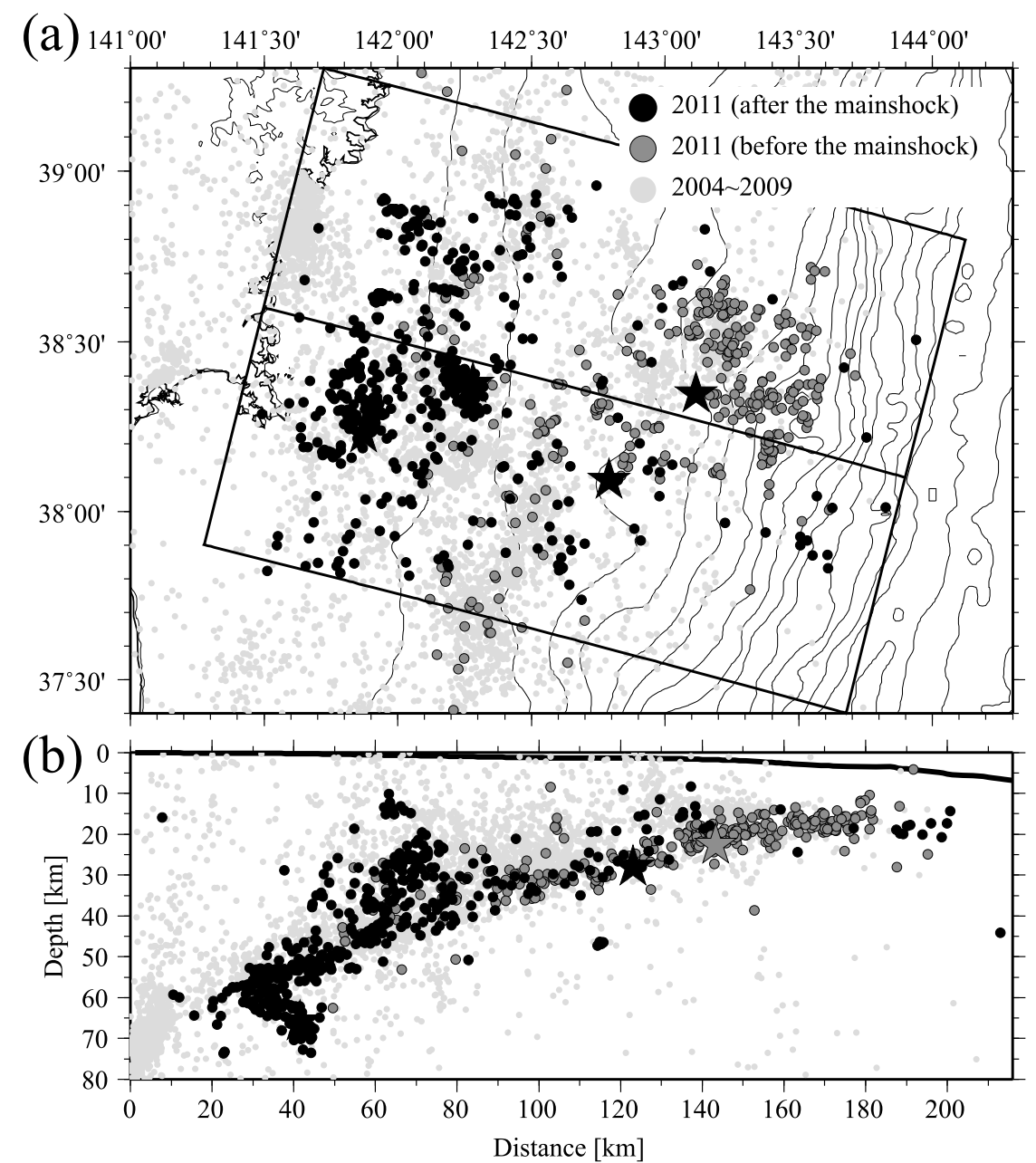

Fig. 4. Hypocenter distribution. The dark gray and black dots show the relocated hypocenters of 2011 earthquakes before and after the 2011 mainshock. Light gray dots show the earthquake that occurred between 2004 and 2009 (background seismicity). (a) Map view. (b) Cross section of the rectangle shown in the map view.

bution. Because most of the earthquakes in this area were thrust-type, the landward dipping planar structure of the relocated hypocenters is more plausible than the scattered pattern of the JMA hypocenters.

The relocated hypocenter of the mainshock (also see Table 2) shifted by $\sim 6 \mathrm{~km}$ westward from the JMA hypocenter. The hypocenter of the largest foreshock, the M-7.3 earthquake on March 9, shows a larger difference with a westward shift of $\sim 13 \mathrm{~km}$ in the epicenter. Although these two major earthquakes have westward relocation shifts (or an eastward mislocation of JMA epicenters), these are not representative of the systematic patterns of shifts in the epicenters due to the relocation. In general, the relocation shifts show an elongated pattern with a large scatter in the EW direction (Fig. 3(c)). The center of the distribution suggests that the relocated epicenters tend to be shifted eastward from the JMA ones. The elongated pat- tern indicates poorer resolutions of the JMA epicenters in the EW direction coinciding with the dip direction of the subducting interface than in the NS (strike) direction.

The obtained hypocenter distribution is shown in Fig. 4. In the figure, the hypocenters of the earthquakes from 2004 to 2009 are also displayed to show the background seismicity in this area. The pre-2011 hypocenters were also relocated by using OBS data, but the selection criteria applied to the pre-2011 earthquakes were eased because the number and density of OBSs were smaller for the early observation period. Nevertheless, the method of hypocenter determination was identical to that applied to the 2011 earthquakes.

As can be seen in the epicenter distribution, the background seismicity is fairly heterogeneous in space, and forms several clusters of concentrated epicenters separated by zones of almost no seismicity. Most of the epicenters of the earthquakes in 2011 are located in these clusters of 
(a) Before the mainshock
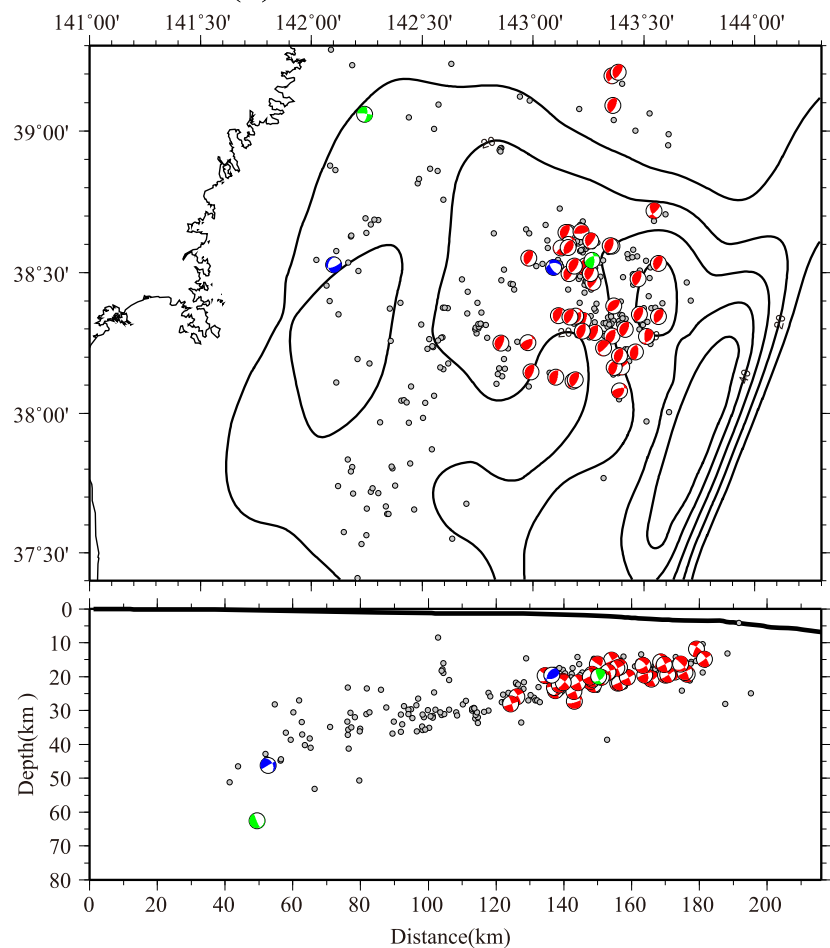

(b) After the mainshock
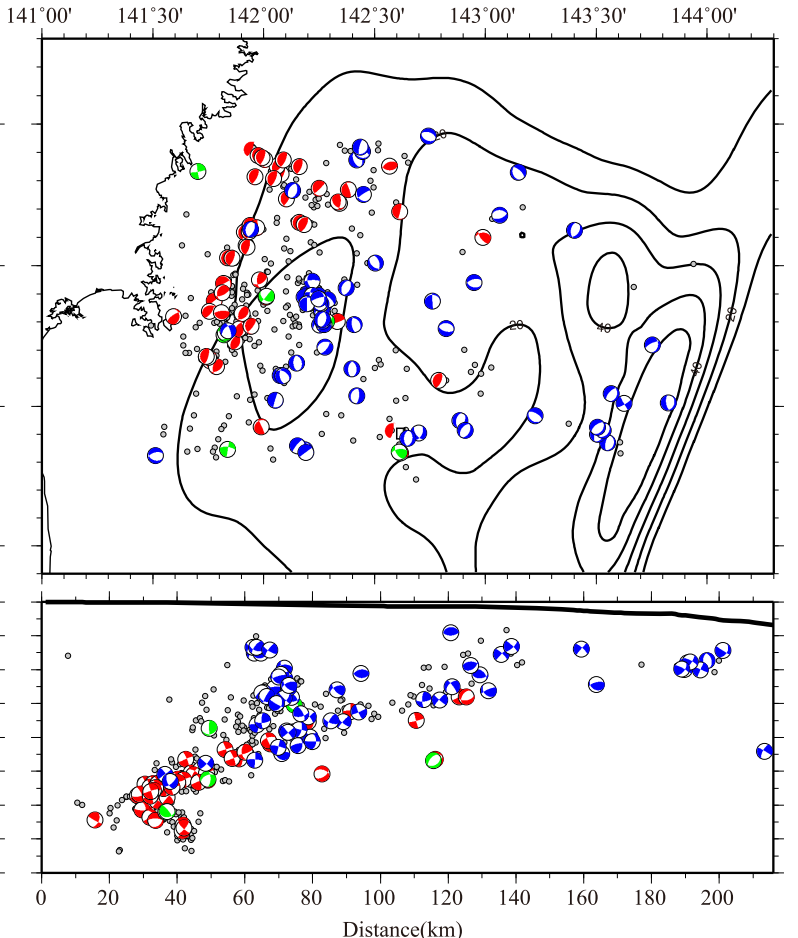

Fig. 5. Hypocenter and focal mechanism distributions of earthquakes that occurred in 2011. The dots show hypocenters. The focal mechanisms estimated by F-net are colored according to its type classified by the rake angle—red: thrust (rake $>45^{\circ}$ ); green: strike-slip $\left(-45^{\circ}<\right.$ rake $<45^{\circ}$ ); and blue: normal-fault (rake $<-45^{\circ}$ ). (a) Before the mainshock (from 1 January, 2011, to the mainshock). (b) After the mainshock (mainshock to 24 May, 2011).

background seismicity. Furthermore, in the focal depth distribution, the pre-2011 and 2011 earthquakes form a similar landward dipping plane. The most notable characteristic of the spatial pattern is an aseismic region (or low seismicity region) along the landward side of the trench axis. Because we relocated the hypocenter locations of earthquakes selected from the JMA catalogue, it is possible that this aseismic region reflects a low detectability of the JMA catalogue along the landward side of the trench axis apart from onshore stations. Here, we checked $b$-values of the relocated earthquakes in the landward and trenchward areas of the mainshock hypocenter. If the difference in detectability is substantial, cutoff magnitudes of frequency-magnitude relations must be different between the two areas. The cutoff magnitude estimated in the landward area was 3.5, whereas that in the trenchward area was $3.5 \sim 4.0$. Considering this small difference, it is very unlikely that a significant number of earthquakes were overlooked only within the narrow zone along the Japan Trench. Furthermore, the existence of this aseismic zone has already been pointed out by previous OBS studies in the Japan Trench area (e.g., Hirata et al., 1985) and this is regarded as a stable structure. Although the spatial distribution of the seismicity changed considerably before and after the occurrence of the $M-9$ Tohokuoki earthquake, as will be explained below, the near-trench zone had a low seismicity compared with the more landward area throughout the observation period. A small number of earthquakes were located within the zone after the mainshock. Judging from their focal depths and mechanisms, they seem to have occurred in the subducting oceanic plate; however, no interplate or shallow crustal events were detected in the trenchward zone.

A detailed examination of the hypocenter distribution shows that the distributions before, and after, the mainshock of the Tohoku-oki earthquake are different from each other. Moreover, this difference is prominent in the case of the focal-depth distribution (Fig. 4). The hypocenters before March 11 tend to concentrate along the dipping plane to a greater degree than those after March 11 . We plotted the focal mechanisms estimated by the F-net waveform monitoring by NIED (http://www.fnet.bosai.go.jp) at the relocated hypocenters from the present study (see Fig. 5). Since thrust-type focal mechanisms are dominant for earthquakes before the mainshock (from 1 January, 2011 to the mainshock, Fig. 5(a)), the shallow dipping plane of the hypocenters is interpreted as the megathrust plane. After the mainshock (from mainshock to 24 May, 2011), hypocenters tended to be located systematically away from the plane, both upward and downward (Fig. 4), indicating that the interplate seismicity diminished while the earthquakes off the plane became dominant. Most of the off-plane earthquakes identified from the focal depth distribution were not thrust type but tended to have normal-fault type mechanisms (Fig. 5(b)), as reported by Asano et al. (2011). Other non-thrust type earthquakes included a large intraslab earthquake ( $M 7.1$, April 7) and a normal faulting shallow earthquake ( $M$ 6.5, March 28) followed by their own aftershocks. In addition to these pronounced activities, there were numerous earthquakes in both the overriding and subducting plates, and the proportion of these intraplate events 
to the interplate ones increased significantly after the mainshock.

Detailed investigations of hypocenter distributions associated with $M<8$ interplate earthquakes using OBS data have indicated that the aftershocks of such interplate earthquakes mostly occurred along the plate boundary, and thrust-type events dominated (e.g., Hino et al., 2000, 2006). The seismicity during March 9 to 11 , which is interpreted as the aftershock activity of the $M-7.3$ earthquake, followed the typical spatial distribution pattern, a concentration of thrust-type events along the plate boundary. However, the pattern changed markedly after the $M-9$ mainshock on March 11. For previous interplate earthquakes, it has been observed that the number of aftershocks tends to be smaller in the vicinity of the zones of large coseismic displacement (i.e., asperity) (e.g., Nagai et al., 2001). In the aftershock activity of the 1994 Sanriku earthquake, a cluster in the overriding plate was found near the low activity region corresponding to the asperity of the earthquake (Hino et al., 2000). Since the coseismic slip amount was the largest in the Miyagi-oki region and further up-dip (e.g., Lay et al., 2011), the change in the seismicity distribution after the mainshock can be interpreted by similar increases in the off plate boundary seismicity near asperities with few aftershocks.

Numerous earthquakes have occurred in the hanging wall of the plate boundary in this area: for example, Uchida et al. (2010) and Yamamoto et al. (2011) have found several earthquake clusters (supra-slab earthquakes) in the hanging wall of the plate boundary along the Japan Trench, including the Miyagi-oki area. However, the exact location of the post- $M 9$ shallow seismicity is not identical to that of the supra-slab earthquakes. It is possible that the spatial patterns of the seismicity in the Miyagi-oki region were changed by the mainshock rupture, in a similar manner to the inland changes in patterns reported by Toda et al. (2011).

\section{Discussion}

\subsection{Foreshock seismicity near the mainshock hypocen- ter}

We examine the foreshock activity in terms of its spatiotemporal variations based on the relocated hypocenter distribution. Map view and space-time plots of the foreshocks are shown in Figs. 6 and 7, respectively. In these spacetime plots, the relocated epicenters are projected onto two orthogonal axes, the $X$-axis is taken in the dip direction of the plate boundary, and the $Y$-axis in the strike direction sub-parallel to the trench strike. The origin is set as the epicenter of the largest foreshock (M7.3, March 9, LFS, Fig. 7).

The first foreshock activity was a moderate ( $M$ 5.5) earthquake on February 16 . The seismicity was relatively modest for the first $\sim 25$ days (period-I). Several $M \sim 5$ foreshocks occurred intermittently during this period and the seismicity presented a swarm-like pattern rather than a mainshock/aftershock pattern. Our relocation results indicate that the foreshock activity initiated at the border between the active seismogenic area of the background seismicity and the aseismic zone near the Japan Trench. Since no foreshocks were located within the aseismic zone, the activity effectively began at the up-dip end of the seismogenic area. It is notable that the foreshock activity in periodI was concentrated along the up-dip edge. Although there was no evident increase in the seismicity in the landward area $(X>0)$, a sequence of foreshocks was observed at $X \sim-30 \mathrm{~km}$. In the space-time plot along the dip $(Y) \mathrm{di}-$ rection, the activity appears to have migrated southward at $\sim 1.8 \mathrm{~km} /$ day.

The foreshock became considerably more active after the LFS occurred, i.e., for the last two days before the mainshock (period-II). The foreshock activity can be interpreted as the aftershocks of the LFS, as explained above. The epicenter of the LFS was located $\sim 20 \mathrm{~km}$ landward of the fringe of the foreshocks in period-I, but the space between the early foreshock activity and the LFS was filled by the foreshocks in period-II (aftershocks of the $M-7.3$ earthquake). A southward migration of the foreshock epicenters can also be observed during period-II, but at a faster $(\sim 6.7$ km/day) speed (Fig. 7(d)). This result supports early studies on foreshock migration based on the onshore stations (Ando and Imanishi, 2011; Kato et al., 2012). Those works had pointed out that the foreshock activity migrated toward the MS, presumably as a result of diffusional propagation of the LSF afterslip. Moreover, in contrast to the active seismicity on the trenchward side of the MS hypocenter, few earthquakes occurred in the down-dip side and the southern side of the MS epicenter (Figs. 7(c) and (d)); this may suggest that the afterslip did not propagate beyond the MS hypocenter. If the foreshocks in period-I were also associated with a slow aseismic slip, as in period-II, the narrow foreshock distribution suggests that the aseismic slip did not propagate in the down-dip direction in the early stage of the foreshock activity.

\subsection{Comparison with seismic structure models}

Since the earthquakes with thrust-type mechanisms are presumably located along the plate boundary, the locations of those hypocenters must be good indicators of the boundary. Further, since most of the foreshocks, including the largest foreshock, were thrust-type events, the shallow dipping plane formed by their relocated hypocenters (Fig. 4) is expected to correspond to the geometry of the plate boundary in this region. On the other hand, the geometry of the plate boundary has been estimated by previous active seismic explorations by travel time analyses of the clear seismic reflection signals from the slab surface. We show a histogram of the relative depths of the foreshocks (Fig. 8) measured from the plate boundary modeled by Ito et al. (2005). Contrary to expectations, the peak does not appear at 0 in the relative depth but at $\sim+5 \mathrm{~km}$. Since the peak is very narrow, the depth discrepancies appear to be almost constant for the sampled hypocenters. These results indicate that the dipping plane of the hypocenter distribution is parallel to the modeled plate boundary, with a depth systematically greater by $\sim 5 \mathrm{~km}$. This discrepancy might be a result of the poor assumption of $P$ - and $S$-wave velocities $\left(V_{p}\right.$ and $\left.V_{s}\right)$ in the shallow sedimentary layer used for our hypocenter determination procedure. As discussed by Hino et al. (2006), the focal depths determined by the OBS data are strongly affected by the $V_{p} / V_{s}$ ratio assumed for 

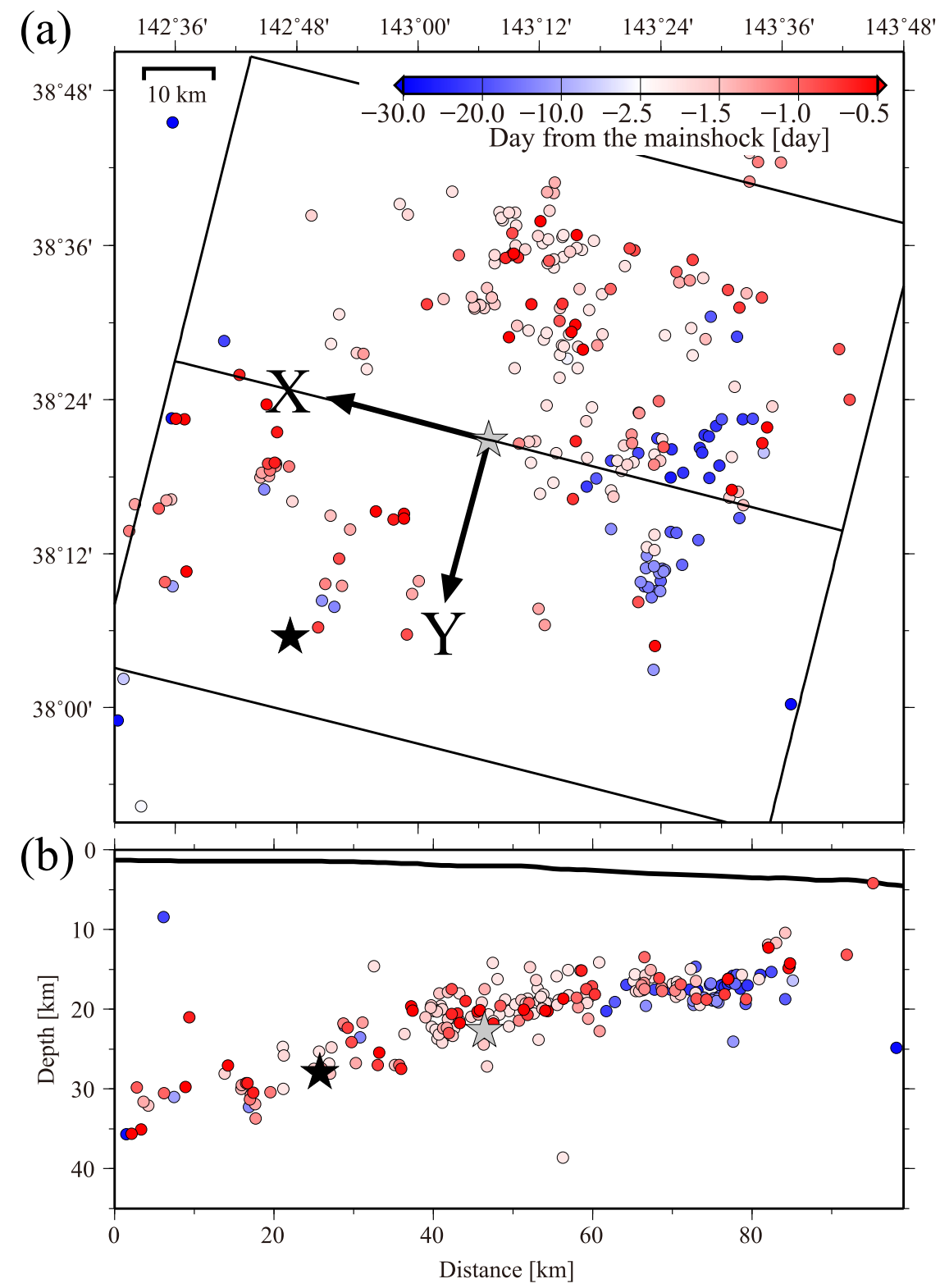

Fig. 6. Hypocenter distribution in the foreshock area shown in Fig. 1(b). Hypocenters that occurred between -30 and 0 days before the mainshock are plotted by dots colored according to the elapsed time from the mainshock. (a) Map view. (b) Cross-section of the rectangle shown in the map view.

the shallow sedimentary layer, but it is difficult to obtain reliable estimations of $V_{p} / V_{s}$. The plate boundary model was derived from $P$-wave based observations without errors due to the uncertainties in $V_{s}$ and can be expected to be better constrained than our focal-depth estimations. Therefore, we regard our focal depths to be biased to a deeper part by $\sim 5$ $\mathrm{km}$. It is possible to obtain optimum $V_{p} / V_{s}$ values that give focal depths that are more consistent with the plate boundary model by further analyses, and this remains a topic for our future work.

In Fig. 9, the relocated hypocenters are plotted on a 2-D $V_{p}$ model obtained by an airgun-OBS wide-angle seismic survey conducted in the Miyagi-oki area (Ito et al., 2005). In the figure, the focal depths are shifted upward by $5 \mathrm{~km}$ from the calculated values to remove the possible bias in our hypocenter solutions. Although this manipulation makes it difficult to interpret the focal depths in an absolute sense, the results are still of valuable to understand how the seis- micity in the Miyagi-oki region is related to the structure variations along the dip direction. After shifting the focal depths, the mainshock (and largest foreshock) are still deeper than the plate boundary and plane formed by the thrust-type earthquakes. Hino et al. (2006) determined the hypocenter distribution of the main- and aftershocks of the 2005 Off Miyagi Prefecture earthquake and reported a similar discrepancy of the mainshock from the plate boundary. This result might be caused by ill-conditioned pickings of $S$-wave arrival time, or the lack of those of mainshock and largest foreshocks at OBS stations.

The thickness of the overriding Tohoku arc crust under the Miyagi-Oki region is approximately $20 \mathrm{~km}$, and the plate boundary meets the Moho (crust-mantle boundary) of the overriding crust at this depth. The location of the mainshock hypocenter almost coincides with that of the intersection of the plate boundary and the Moho. Since the activity of the foreshocks was significantly different on 

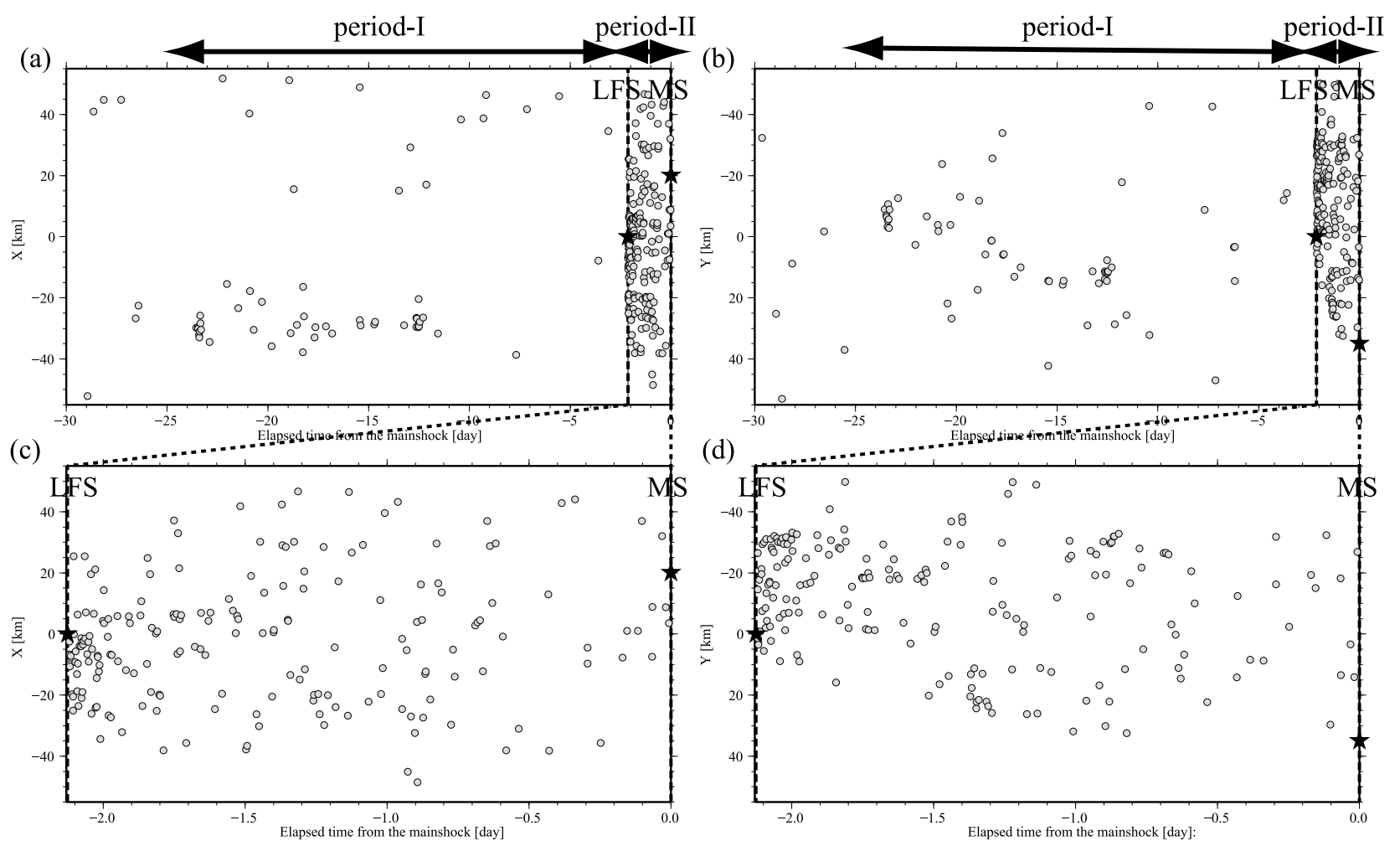

Fig. 7. Space-time distribution projected using two orthogonal axes shown in Fig. 6. The stars show the LFS (Largest ForeShock) and MS (MainShock). (a) Space-time plot between -30 and 0 days before the MS of the seismicity along the dip of the subducting plate boundary ( $X$-axis). (b) Space-time plot between -30 and 0 days before the MS of the seismicity along the strike of the subducting plate boundary ( $Y$-axis). (c) Space-time plot of the seismicity along the $X$-axis from the LFS to the MS. (d) Space-time plot of the seismicity along the $Y$-axis from the LFS to the MS.

the trenchward and landward sides of the hypocenter of the mainshock, the difference can be interpreted in terms of the differences in the structure above the plate boundary. On the trenchward side of the mainshock hypocenter, where most of the foreshocks occurred, the shallow dipping subducting Pacific slab contacts the continental crustal layer (slab-crust contact zone). In contrast, no significant foreshocks were observed in the landward side of the mainshock hypocenter, where the Pacific slab contacts the forearc mantle (slabmantle contact zone).

The mainshock hypocenter can be a good reference point to compare the rupture process of the Tohoku-oki earthquake and the seismic structure near the plate boundary. In many studies (e.g., Lay et al., 2011; Yagi and Fukahata, 2011), the estimated coseismic slip amount was substantially larger toward the trenchward side of the hypocenter than the landward (down-dip) side. This tendency can be interpreted as the slab-crust contact zone accommodating more coseismic slip than the slab-mantle contact zone. In the slab-crust contact zone, the interplate seismicity has been active, including the occurrence of foreshocks, until the mainshock took place, but it diminished drastically in the aftershock activity. In the slab-mantle contact zone, although the number of thrust-type earthquakes decreased after the mainshock, they did not vanish, in contrast to the slab-crust contact zone.

Besides the difference of the hanging wall side materials, the geometry of the subducting Pacific slab may be relevant to the spatial pattern of the seismicity. In the Miyagi-Oki region, Ito et al. (2005) pointed out that the slab abruptly

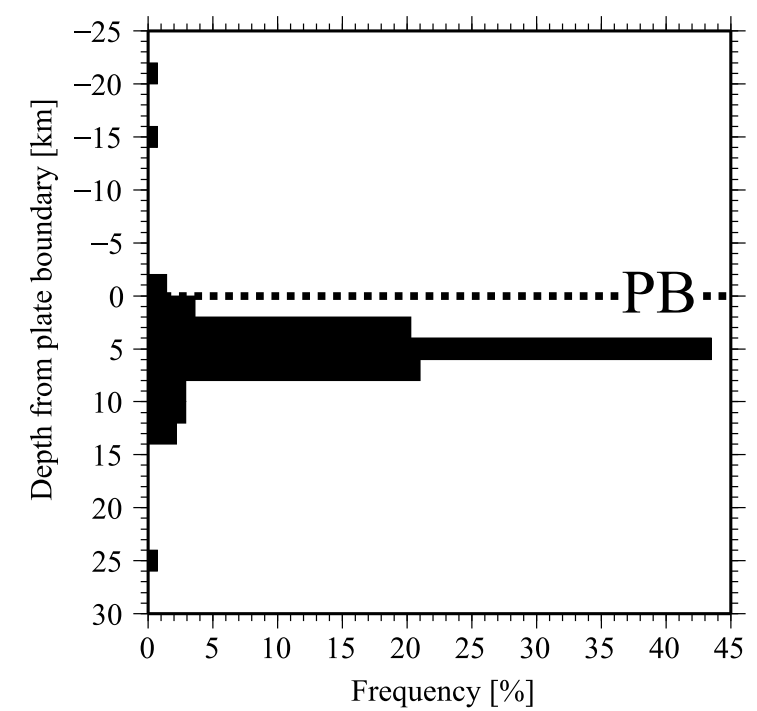

Fig. 8. Histogram of the relative depths of the foreshocks that occurred in the foreshock area (Fig. 1(b)) and between -30 and 0 days before the mainshock, measured from the plate boundary modeled by Ito et al. (2005).

changes its dip angle and further that the spatial extent of the rupture areas of the $M<8$ class Miyagi-Oki earthquakes seems to be delimited by the bending points of the slab. Comparing the location of the slab bending points (at $\sim 50$ and $\sim 110 \mathrm{~km}$ in Fig. 9, according to Ito et al., 2005) with the spatial pattern of the foreshock/aftershock activity of the Tohoku-Oki earthquake, it seems that the trenchward 


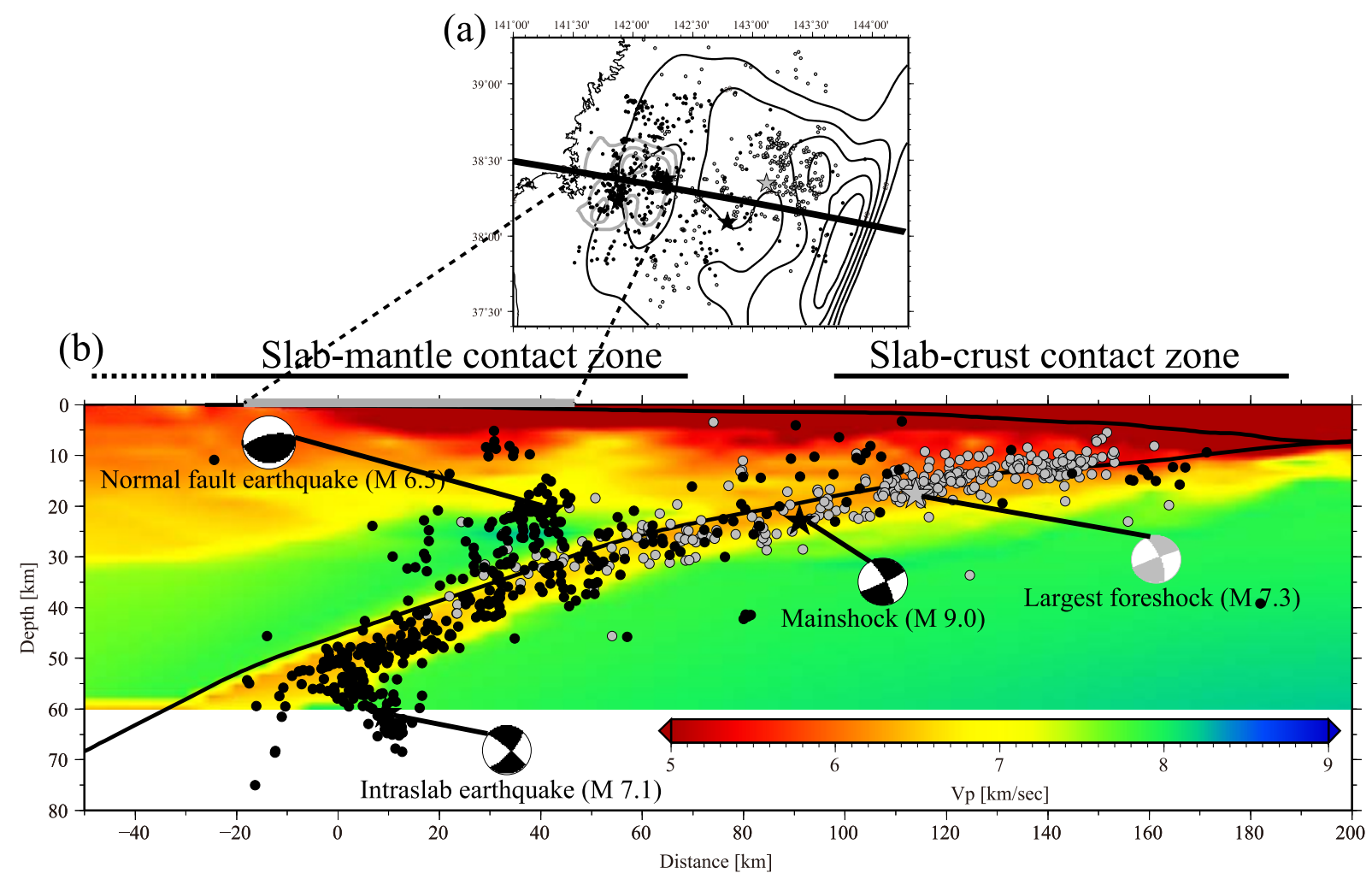

Fig. 9. (a) Map of the seismic survey line used in Ito et al. (2005). Black and gray contours are rupture areas of the 2011 (Lay et al., 2011 ) and 1978 (Yamanaka and Kikuchi, 2004) earthquakes. (b) Comparison between the hypocenter locations and the 2-D $V_{p}$ model obtained by Ito et al. (2005). The earthquakes before and after the 2011 mainshock are shown by the gray and black dots, respectively. Focal mechanisms of large earthquakes estimated by F-net are shown.

bending point delimits concentrated foreshocks. The bending of the plate boundary may cause a variation of stress around the plate boundary, and as a result seismicity variation might occur in response to that stress distribution.

Although it is difficult to single out the seismogenic mechanism from a number of proposed models, more detailed discussions of the relationship between hypocenter locations, fault segmentation and the material structure contrast around the plate boundary, are important for considering the seismogenic mechanism in terms of metamorphic environments (e.g., Hyndman and Peacock, 2003). It is necessary for those discussions to obtain a detailed seismic structure, including the trenchward area. This is part of our future work, as well as verifying if focal depths and modeled plate boundary locations are consistent.

Our list of hypocenter locations relocated by the present study using OBSs data can be downloaded from http://www.aob.geophys.tohoku.ac.jp/ suzuki/hypoEPS2012suzuki.dat.

\section{Conclusion}

In this study, we have relocated the hypocenters of the foreshocks, mainshock, and aftershocks of the 2011 off the Pacific coast of Tohoku earthquake that occurred on March 11,2011 , by using the arrival time data obtained by 15 temporally deployed OBSs, 3 cabled OBSs, and onshore seismic stations. Although the seismicity in the MiyagiOki region was high in the central part of the Japan Trench subduction zone, the spatial distribution of the hypocenters changed significantly in response to the $M-9$ mainshock occurrence throughout the observation period. The earthquakes prior to the mainshock formed a landward dipping plane indicating active interplate seismic activity. In contrast, the number of interplate earthquakes, identified by the focal depths and mechanisms, decreased considerably after the mainshock, while intraplate activity, off the plate boundary, occurred simultaneously in both the overriding and subducting plates.

The foreshock activity started near the up-dip limit of the active interplate seismicity and no foreshocks were located in the aseismic near-trench zone, as identified by the background seismicity. The area of the foreshock activity showed minor expansions along the strike of the plate boundary but almost no down-dip propagation until a large foreshock ( $M$ 7.3) occurred on March 9. After the $M-7.3$ foreshock, the seismicity rapidly increased with migration toward the mainshock hypocenter. The foreshock activity was observed mainly on the trenchward side of the mainshock hypocenter, where the subducting Pacific slab contacts the crust of the Tohoku arc, but did not expand further landward where the slab contacts the forearc mantle.

Acknowledgments. We thank T. Lay and an anonymous reviewer for providing thoughtful reviews, which helped us to improve this manuscript. This study was supported by the MEXT project, "Evaluation and disaster prevention research for the coming Tokai, Tonankai and Nankai earthquakes". We thank the captain, crews and scientists on board several research vessels for their kind support of the OBS observations. We are grateful to NIED and JMA for allowing us to use focal mechanisms or arrival time data at 
onshore stations. Figures were prepared using Generic Mapping Tools software (Wessel and Smith, 1995).

\section{References}

Ando, R. and K. Imanishi, Possibility of $M_{\mathrm{w}} 9.0$ mainshock triggered by diffusional propagation of after-slip from $M_{\mathrm{w}} 7.3$ foreshock, Earth Planets Space, 63, 767-771, 2011.

Asano, Y., T. Saito, Y. Ito, K. Shiomi, H. Hirose, T. Matsumoto, S. Aoi, S. Hori, and S. Sekiguchi, Spatial distribution and focal mechanisms of aftershocks of the 2011 off the Pacific coast of Tohoku Earthquake, Earth Planets Space, 63, 669-673, 2011.

DeMets, C., R. G. Gordon, D. F. Argus, and S. Stein, Effect of recent revisions to the geomagnetic reversal time scale on estimates of current plate motions, Geophys. Res. Lett., 21, 2191-2194, 1994.

F-net, NIED, NIED CMT solutions, http://www.fnet.bosai.go.jp, 2011.

Hino, R., S. Ito, H. Shiobara, H. Shimamura, T. Sato, T. Kanazawa, J. Kasahara, and A. Hasegawa, Aftershock distribution of the 1994 Sanriku-oki earthquake (Mw 7.7) revealed by ocean bottom seismographic observation, J. Geophys. Res., 105, 21697-21710, 2000.

Hino, R., Y. Yamamoto, A. Kuwano, M. Nishino, T. Kanazawa, T. Yamada, K. Nakahigashi, K. Mochizuki, M. Shinohara, K. Minato, G. Aoki, N. Okawara, M. Tanaka, M. Abe, E. Araki, S. Kodaira, G. Fujie, and Y. Kaneda, Hypocenter distribution of the main- and aftershocks of the 2005 Off Miyagi Prefecture Earthquake located by ocean bottom seismographic data, Earth Planets Space, 58, 1543-1548, 2006.

Hirata, N., T. Kanazawa, K. Suehiro, and H. Shimamura, A seismicity gap beneath the inner wall of the Japan trench as derived by ocean bottom seismography measurement, Tectonophysics, 112, 193-209, 1985.

Hyndman, D. R. and S. M. Peacock, Serpentinization of the forearc mantle, Earth Planet. Sci. Lett., 212, 417-432, 2003.

Ito, A., G. Fujie, S. Miura, S. Kodaira, and Y. Kaneda, Bending of the subducting oceanic plate and its implication for rupture propagation of large interplate earthquakes off Miyagi, Japan, in the Japan Trench subduction zone, Geophys. Res. Lett., 32, doi:10.1029/2004GL022307, 2005.

Kato, A., K. Obara, T. Igarashi, H. Tsuruoka, S. Nakagawa, and N. Hirata, Propagation of slow slip leading up to the $2011 \mathrm{Mw} 9.0$ Tohoku-Oki Earthquake, Science, 335, 705-708, 2012.

Lay, T., C. J. Ammon, H. Kanamori, L. Xue, and M. J. Kim, Possible large near-trench slip during the $2011 M_{\mathrm{W}} 9.0$ off the Pacific coast of Tohoku Earthquake, Earth Planets Space, 63, 687-692, 2011.

Nagai, R., M. Kikuchi, and Y. Yamanaka, Comparative study on the source process of recurrent large earthquakes in Sanriku-oki region: The 1968 Tokachi-oki earthquake and the 1994 Sanriku-oki earthquake, J. Seismol. Soc. Jpn., 52, 267-289, 2001 (in Japanese with English abstract).

Okada, T., T. Yaginuma, N. Umino, T. Kono, T. Matsuzawa, S. Kita, and A. Hasegawa, The 2005 M7.2 MIYAGI-OKI earthquake, NE Japan:
Possible rerupturing of one of asperities that caused the previous M7.4 earthquake, Geophys. Res. Lett., 32, doi:10.1029/2005GL024613, 2005.

Sakai, S., T. Yamada, M. Shinohara, H. Hagiwara, T. Kanazawa, K. Obana, S. Kodaira, and Y. Kaneda, Urgent aftershock observation of the 2004 off the Kii Peninsula Earthquake using ocean bottom seismometers, Earth Planets Space, 57, 363-368, 2005.

Toda, S., R. S. Stein, and J. Lin, Widespread seismicity excitation throughout central Japan following the $2011 \mathrm{M}=9.0$ Tohoku earthquake and its interpretation by Coulomb stress transfer, Geophys. Res. Lett., 38 , L00G03, doi:10.1029/2011GL047834, 2011.

Uchida, N., S. H. Kirby, T. Okada, R. Hino, and A. Hasegawa, Supraslab earthquake clusters above the subduction plate boundary offshore Sanriku, northeastern Japan: Seismogenesis in a graveyard of detached seamounts?, J. Geophys. Res., 115, B09308, doi:10.1029/2009JB006797, 2010.

Wessel, P. and W. H. F. Smith, New version of the Generic Mapping Tools released, Eos Trans. AGU, 76, 329, 1995.

Wu, C., K. Koketsu, and H. Miyake, Source process of the 1978 and 2005 Miyagi-Oki, Japan, earthquake: Repeated rupture of asperities over successive large earthquakes, J. Geophys. Res., 113, B08316, doi:10.1029/2007JB005189, 2008.

Yagi, Y. and Y. Fukahata, Rupture process of the 2011 Tohoku-oki earthquake and absolute elastic strain release, Geophys. Res. Lett., 33, L19307, doi:10.1029/2011GL048701, 2011.

Yamamoto, Y., R. Hino, K. Suzuki, Y. Ito, T. Yamada, M. Shinohara, T. Kanazawa, G. Aoki, M. Tanaka, K. Uehira, G. Fujie, Y. Kaneda, T. Takanami, and T. Sato, Spatial heterogeneity of the mantle wedge structure and interplate coupling in the NE Japan forearc region, Geophys. Res. Lett., 35, L23304, doi:10.1029/2008GL036100, 2008.

Yamamoto, Y., R. Hino, and M. Shinohara, Mantle wedge structure in the Miyagi Prefecture forearc region, central northeastern Japan arc, and its relation to corner-flow pattern and interplate coupling, J. Geophys. Res., 116, B10310, doi:10.1029/2011JB008470, 2011.

Yamanaka, Y. and M. Kikuchi, Asperity map along the subduction zone in northeastern Japan inferred from regional seismic data, J. Geophys. Res., 109, B07307, doi:10.1029/2003JB002683, 2004.

Zhang, H. and C. H. Thurber, Double-Difference Tomography: The Method and Its Application to the Hayward Fault, California, Bull. Seismol. Soc. Am., 93, 1875-1889, 2003.

Zhang, H. and C. H. Thurber, Development and applications of doubledifference seismic tomography, Pure Appl. Geophys., 163, 373-403, doi:10.1007/s00024-005-0021-y, 2006.

K. Suzuki (e-mail: suzuki@aob.gp.tohoku.ac.jp), R. Hino, Y. Ito, Y. Yamamoto, S. Suzuki, H. Fujimoto, M. Shinohara, M. Abe, Y. Kawaharada, Y. Hasegawa, and Y. Kaneda 